\title{
1 Activity budget and gut microbiota across reproductive states in wild, female capuchin
} 2 monkeys in a seasonal dry forest

4 Shasta E. Webb ${ }^{1 *}$, Joseph D. Orkin ${ }^{2,3}$, Rachel E. Williamson ${ }^{1}$, Amanda D. Melin ${ }^{1,4 *}$

*Authors for correspondence

81 Department of Anthropology and Archaeology, University of Calgary, Calgary, Canada

92 Institut de Biologia Evolutiva, Universitat Pompeu Fabra-CSIC, Barcelona, Spain

103 Département d'anthropologie, Université de Montréal, Montréal, Canada

114 Department of Medical Genetics, Cumming School of Medicine, University of Calgary,

12 Calgary, Canada

\section{ABSTRACT}

16 Energy demands associated with pregnancy and lactation are significant forces in mammalian

17 evolution. To mitigate increased energy costs associated with reproduction, female mammals

18 have evolved behavioral and physiological responses. Some species alter activity to conserve

19 energy during pregnancy and lactation, while others experience changes in metabolism and fat

20 deposition. Restructuring of gut microbiota with shifting reproductive states may also help

21 females increase energy harvest from foods, especially during pregnancy. Here, we combine life

22 history data with $>13,000$ behavioral scans and $>300$ fecal samples collected longitudinally

23 across multiple years from 33 white-faced capuchin monkey females to examine the

24 relationships among behavior, gut microbiota composition, and reproductive state. We used 16S-

25 based amplicon sequencing and the DADA2 pipeline to analyze microbial diversity and putative

26 functions. Reproductive state explained some variation in activity, but overall resting and

27 foraging behaviours were relatively stable across the reproductive cycle. We found evidence for

28 increases in biotin synthesis pathways among microbes in lactating females, and that microbial

29 community dissimilarity among the states was small but significant. Otherwise, gut microbiota

30 structure and estimated functions were not substantially different among reproductive states. 
31 These data contribute to a broader understanding of plasticity in response to physiological shifts

32 associated with mammalian reproduction.

\section{INTRODUCTION}

35 The demands of pregnancy and lactation have been an influential force throughout mammalian

36 evolution. Female mammals experience discrete stages of the reproductive cycle, including

37 cycling, pregnancy, and lactation, but variation across mammalian taxa exists in response to

38 cycling parameters, litter size, birth weight, gestation length, weaning age, weaning mass, and

39 interbirth interval (Gittleman \& Thompson, 1988). Lactation is typically the most energetically

40 demanding stage of the reproductive cycle because milk production and other aspects of infant

41 care, incuding infant carrying, require considerable energy above basal metabolic function

42 (Clutton-Brock et al., 1989; Dewey, 1997; Gittleman \& Thompson, 1988). Pregnancy is the

43 second most energetically-demanding state, and non-pregnant, non-lactation states (i.e. cycling

44 and non-cycling pauses) are the least energetically costly (Dufour \& Sauther, 2002; Serio-Silva

45 et al., 1999). In addition to heightened net energy demands, pregnancy and lactation also

46 introduce increased protein and other nutrient requirements to fuel fetal and infant growth

47 (Dewey, 1997; National Research Council, 2003). Energy requirements typically increase as a

48 fetus develops during pregnancy; after parturition, energy demands continue to increase as the

49 mother produces milk (Ellison, 2003; Emery Thompson, 2013; Villar et al., 1992). As the infant

50 grows and needs more milk combined with larger infant size, energy demand on the mother

51 continues to grow. During the final stages of lactation, once the infant becomes semi-

52 independent in the lead-up to weaning, energy requirements related to infant care decrease

53 (Figure 1). 


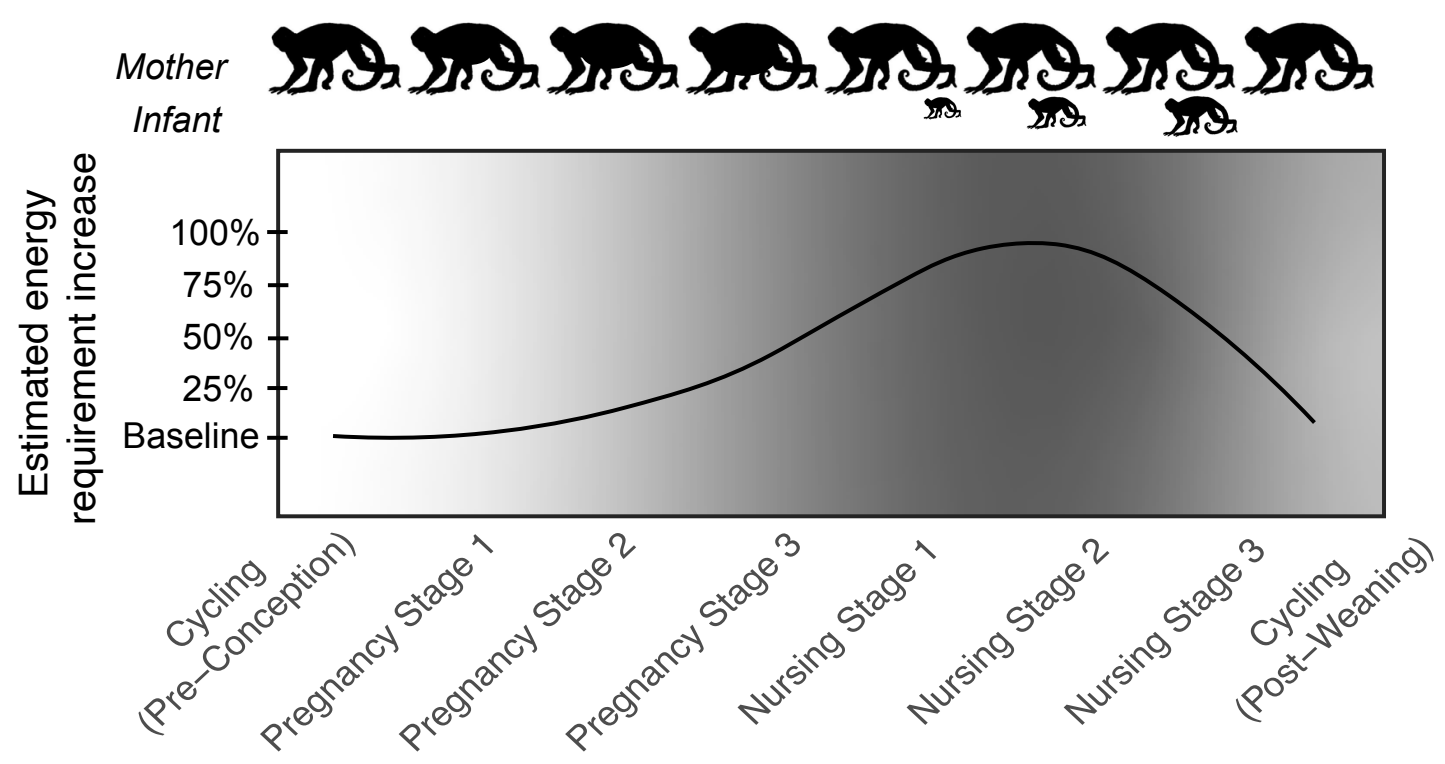

59 Figure 1. Visualization of estimated increases in energy requirements during the reproductive

60 cycle of a non-human primate. Female primates face a $25 \%$ increase in daily energy

61 requirements during gestation, and up to a 50-100\% increase during lactation (Key \& Ross,

62 1999).

63 Mammals vary widely in the length and energy costs of reproduction and have evolved multiple

64 strategies in response. Adaptations include behavioral responses to seasonal fluctuations in food

65 availability. For example, harbour seals (Phoca vitulina) and other migratory species travel to

66 specific breeding sites and feeding sites, and exhibit strictly seasonal breeding that is tied to food

67 abundance in their environment (Bowen et al., 2001). For mammals that are not constrained by

68 migratory patterns or strict seasonal breeding, behavioral flexibility_including modulating

69 energy expenditure, foraging rates, and food choice - offers a strategy to mitigate increased

70 energy costs of pregnancy and lactation. Primates, including humans, exemplify these behvioral

71 strategies. While some primates conserve energy during costly reproductive stages by resting for

72 larger proportions of the day (e.g. red-ruffed lemurs [Varecia rubra], (Vasey, 2005); green

73 monkeys [Cercopithecus sabaeus] (Harrison, 1983)), others increase energy intake, either by

74 foraging for longer periods of the day (e.g. yellow baboons (Papio cynocephalus) (Altmann, 
2001)) or by increasing their intake rate of foods (e.g. white-faced capuchins [Cebus capucinus imitator] (McCabe \& Fedigan, 2007)).

Adaptations to the demands of the reproductive cycle also include physiological changes that occur within the mother. For example, changing patterns of fat gain enable females to accumulate fat stores during pregnancy that they can draw from during lactation. Humans typically experience increased fat deposition during pregnancy, even in cases when they are

81 experiencing food stress (Poppitt et al., 1993). Similar results were found in a study of captive

82 bonobos (Pan paniscus), in which pregnant females did not lose weight while experiencing

83 caloric restriction (Deschner et al., 2008). Sufficient temporary fat gain during pregnancy

84 supports efficient and healthy development of infants. Too little fat gain may lead to increased

85 periods of lactation and increased interbirth interval (e.g. humans (Lunn et al., 1984)), while too

86 much fat gain during gestation can lead to birth complications (e.g. domestic canines and felines

87 (Fontaine, 2012)).

Research on humans suggests that pregnancy is also associated with changes in gut microbial communities (DiGiulio et al., 2015; Koren et al., 2012; Smid et al., 2018). These changes, which

90 include reduced diversity of microbes, shifts in prominent bacterial phyla associated with energy

91 harvest, and shifts in putative metabolic pathways related to energy absorption are linked to

92 metabolic disease states in non-pregnant individuals. However, in the context of reproductive

93 demands, they may serve an adaptive role in increasing energy harvest from food during times of

94 increased energy need for fetal development and allow for increased fat storage to cope with

95 costs of lactation (Edwards et al., 2017; Koren et al., 2012). In non-human mammals, evidence

96 suggests gut microbiota change during reproduction (e.g. Tibetan macaques (Sun et al., 2021)),

97 and shifts may be hormonally mediated (Mallott et al., 2020). However, other researchers have

98 found that composition and predicted function of individuals' gut microbiota remained relatively

99 static throughout pregnancy and into early lactation (Jost et al., 2013). These contrasting findings

100 may be due to differences in study design, methods, and sample species and population.

101 Alternatively, they may indicate that the degree to which the gut microbiome can shift during

102 pregnancy is constrained or enabled by external factors. 
103 Behavioral and gut microbial changes might interact to address the demands of pregnancy and

104 lactation. However, few studies have combined behavioral and gut microbial data tracked

105 throughout pregnancy and lactation to understand the nuances of how mammals in a wild setting

106 cope with increased energy requirements. Here, we combine behavioral and gut microbial data

107 from a well-studied population of wild non-human primates to examine the strategy or

108 combination of strategies that female primates employ to address the increased energetic costs of

109 pregnancy and lactation. To examine behavioral and gut microbial community flexibility as they

110 relate to the reproductive cycle, we studied a population of omnivorous, wild white-faced

111 capuchin monkeys that exhibit moderately seasonal breeding. Specifically, we examine white-

112 faced capuchin monkey responses to changing reproductive stages over the course of 5 years in a

113 seasonal dry forest. We combine a robust data set of $>13000$ behavioral scans with $>300$ fecal

114 samples collected from 33 monkeys to study behavioral and gut microbial responses to

115 reproduction in a species that inhabits a dynamic and seasonal ecosystem. Our first aim was to

116 compare activity budgets of white-faced capuchins among and within cycling, pregnancy, and

117 nursing stages. We predict that if capuchins employ an "energy conservation" approach during

118 pregnancy and nursing, then females will rest more in stages of higher energy demand compared

119 to stages of lower energy demand. Conversely, if capuchins employ an "energy maximization"

120 approach during pregnancy and lactation, then females will forage for larger proportions of their

121 day compared to cycling capuchins. Our second aim was to investigate gut microbial changes in

122 female capuchins among cycling, pregnant, and nursing states. We predict that gut microbiota

123 will exhibit characteristics associated with increased capacity for energy harvest during periods

124 of highest energy demand during pregnancy. We also predict that females' gut microbiota will

125 exhibit an increase in relative abundance of putative metabolic pathways related to energy

126 metabolism and carbohydrate transport during pregnancy. Given the demonstrated potential for

127 ecological and social factors to influence behavioral or gut microbial flexibility in this species,

128 we additionally examine the potential effects of precipitation, temperature, diet, fruit biomass in

129 the environment, and dominance rank on activity budget and gut microbial communities. 


\section{RESULTS}

134

135 Aim 1: Compare activity budgets of white-faced capuchins among and within cycling,

136 pregnancy, and nursing stages

138 To visualize overall activity budget shifts across the reproductive cycle, we combined related

139 behaviors (see Ethogram, Supplemental Table 1) into six general categories: Foraging, Resting,

140 Social Affiliation, Social Aggression, Travel, and Other. We calculated proportions of each

141 category per total scans per day (Figure 2).

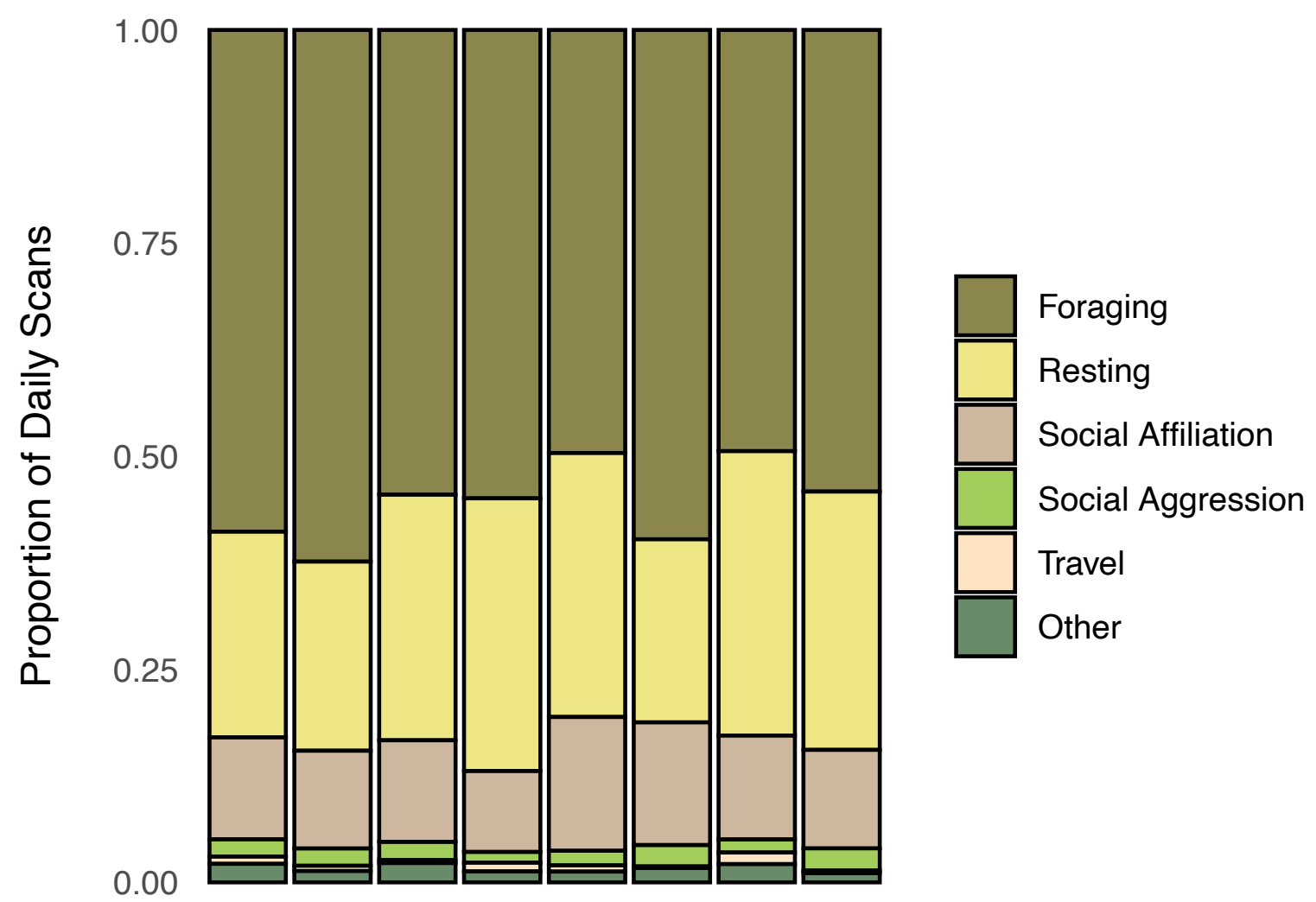


142 Figure 2. Proportions of daily scans spent in each of six behavioral categories across the

143 reproductive cycle. These data represent raw counts of scans per behavior per day divided by

144 total scans recorded per day.

Resting activity within and among reproductive states

A generalized linear mixed model of resting activity that included reproductive state outperformed a null model excluding this variable, suggesting some variation in resting behavior was explained by reproductive stage. High social rank was significantly negatively related to total resting scans $($ Estimate $=-0.13, \mathrm{SE}=0.06, \mathrm{Z}-$ Value $=-2.16, \mathrm{p}=0.03)$, indicating that higher ranking individuals rested less often than lower or mid-ranking individuals. Maximum temperature was significantly positively related to total resting scans indicating that monkeys rested more often in hot temperatures $($ Estimate $=0.22, \mathrm{SE}=0.02, \mathrm{Z}$-Value $=10.35, \mathrm{p}<0.001$ ) (Supplemental Table 2). Incident Rate Ratios for all predictors are presented in Figure 3a and values reported in Supplemental Table 2. Predicted counts of resting scans per day are visualized in Figure $3 \mathrm{~b}$ and demonstrate that resting increased throughout pregnancy and early nursing, dipped in mid-nursing, and increased again in late nursing. However, variation was minor and we did not find significant pairwise differences among the eight individual reproductive stages.

A

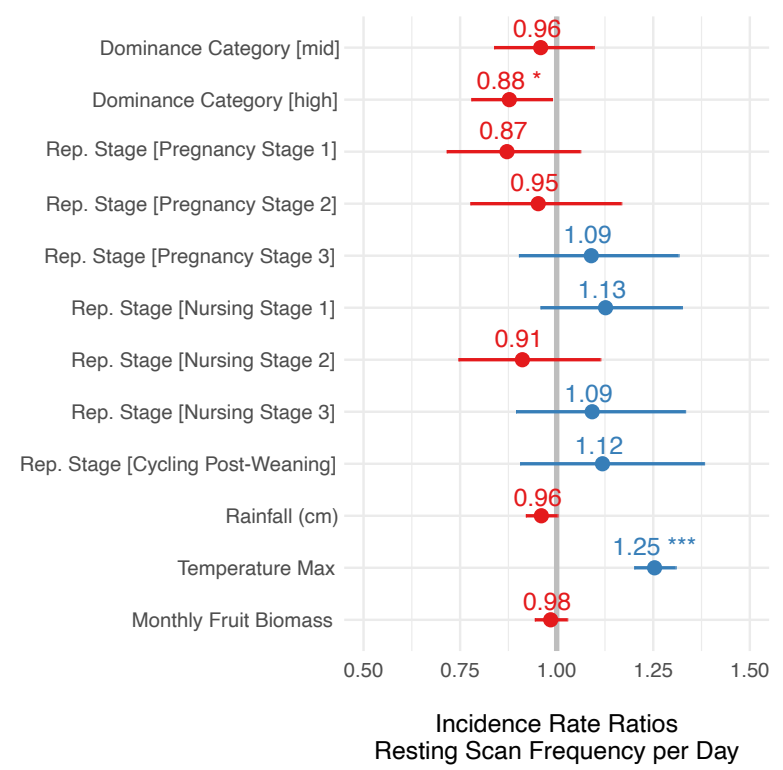

B

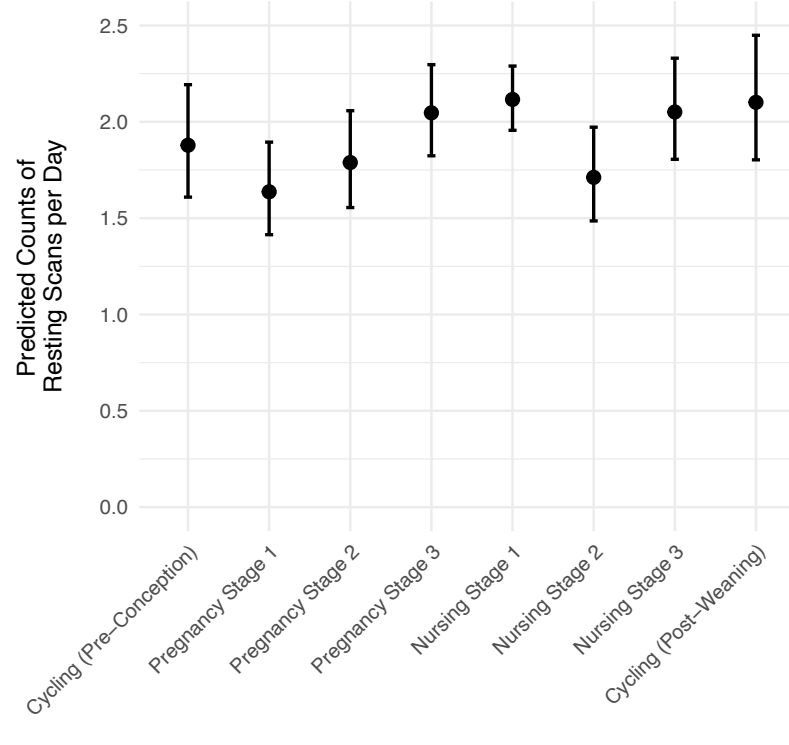


160 Figure 3. Incidence rate ratios (IRR) and standard error (A) for predictors from a GLMM of 161 resting scans per day. The reference dominance category is low social rank; the reference 162 reproductive stage is cycling (pre-conception). The grey vertical line represents "no effect".

163 Values to the right of the grey line represent positive effects and values to the left represent 164 negative effects. Significant predictors $(\mathrm{p}<0.05)$ are denoted with asterisks. We present an 165 alternative way to visualise the effect of reproductive stage on resting activity by plotting the 166 predicted number of resting scans per day for each level of reproductive stage variable (B).

Foraging activity within and among reproductive states

The generalized linear mixed model of foraging activity that included reproductive state outperformed a null model excluding this variable. Females in Nursing Stage 1 exhibited significantly fewer foraging scans per day compared to other stages (Estimate $=-0.13, \mathrm{SE}=0.05$, $\mathrm{Z}$-Value $=-2.45, \mathrm{p}=0.01)$. Ecological variables including rainfall, daily maximum temperature, and estimates fruit biomass were also significantly correlated with foraging scans per day and values are reported in Supplemental Table 2). Incident Rate Ratios for all predictors in the model are presented in Figure 4a and we visualized predicted counts of foraging scans per day in Figure 4b. These predicted counts, which take into account all other predictors in the foraging model, suggest that foraging scans steadily decreased throughout pregnancy and into early nursing before increasing throughout late nursing and into post-weaning cycling. 
A

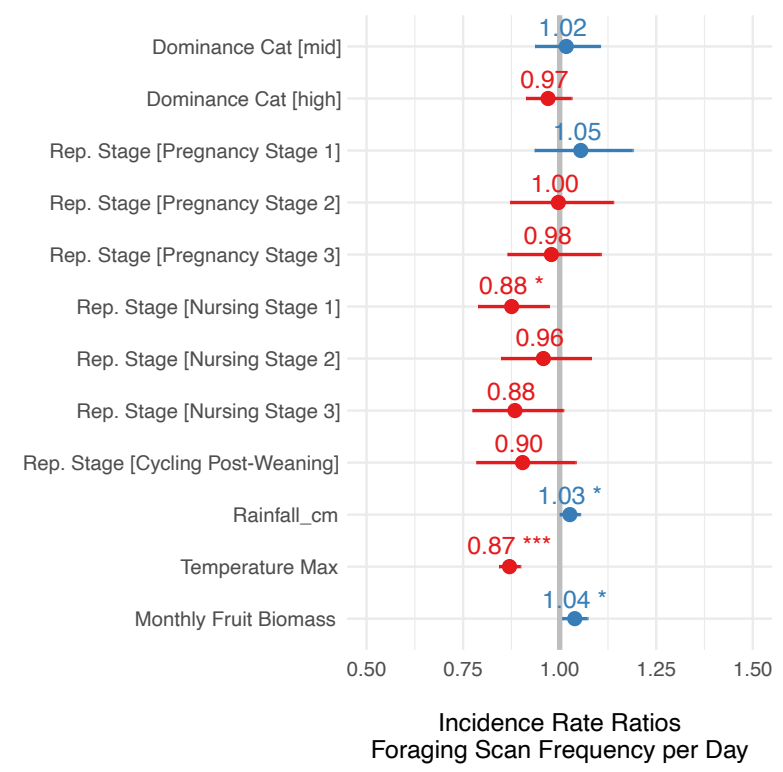

B

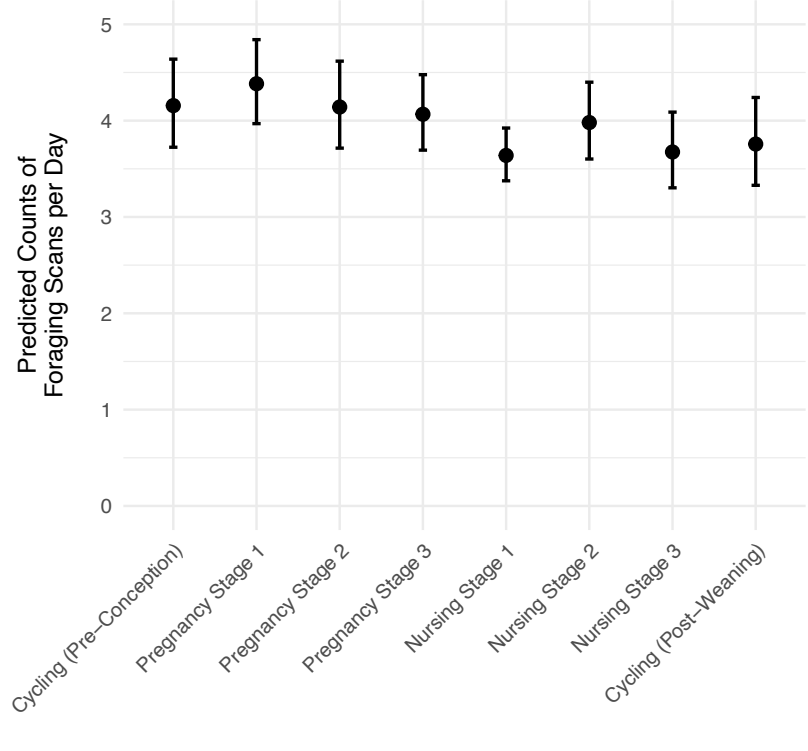

Figure 4. Incidence rate ratios (IRR) and standard error (A) for predictors from GLMM of foraging scans per day. The reference dominance category is low social rank; the reference reproductive stage is cycling (pre-conception). The grey vertical line represents "no effect". Values to the right of the grey line represent positive effects and values to the left represent negative effects. Significant predictors $(\mathrm{p}<0.05)$ are denoted with asterisks. We present an alternative way to visualise the effect of reproductive stage on foraging activity by plotting the predicted number of resting scans per day for each level of reproductive stage variable (B).

\section{Aim II: Investigate gut microbial changes in female capuchins among cycling, pregnant, and nursing states}

\section{Gut microbial community structure remained consistent among reproductive states}

Overall, when we examined broad metrics of gut microbial community structure, we found that reproductive state was not a significant predictor of the Chao1 species richness or Shannon alpha diversity (Supplemental Table 3). Rainfall was significantly negatively correlated with Chao 1 richness (Incidence Rate Ratio $=0.89, \mathrm{CI}=0.83-0.95, \mathrm{p}=0.001$ ), but no other predictors were significant in either model. Reproductive status was not a significant predictor of gut microbial community dissimilarity $\left(\mathrm{DF}=2, \mathrm{~F}=1.275, \mathrm{R}^{2}=0.008, \mathrm{P}=0.163\right)$ and samples from the same 
200 reproductive state did not cluster distinctly (Figure 5). Individual identity accounted for a

201 statistically significant degree of dissimililarity among samples $\left(\mathrm{DF}=28, \mathrm{~F}=1.278, \mathrm{R}^{2}=0.11, \mathrm{P}\right.$

$202=0.003$ ), as did diet type and rainfall (Supplemental Table 3).

A

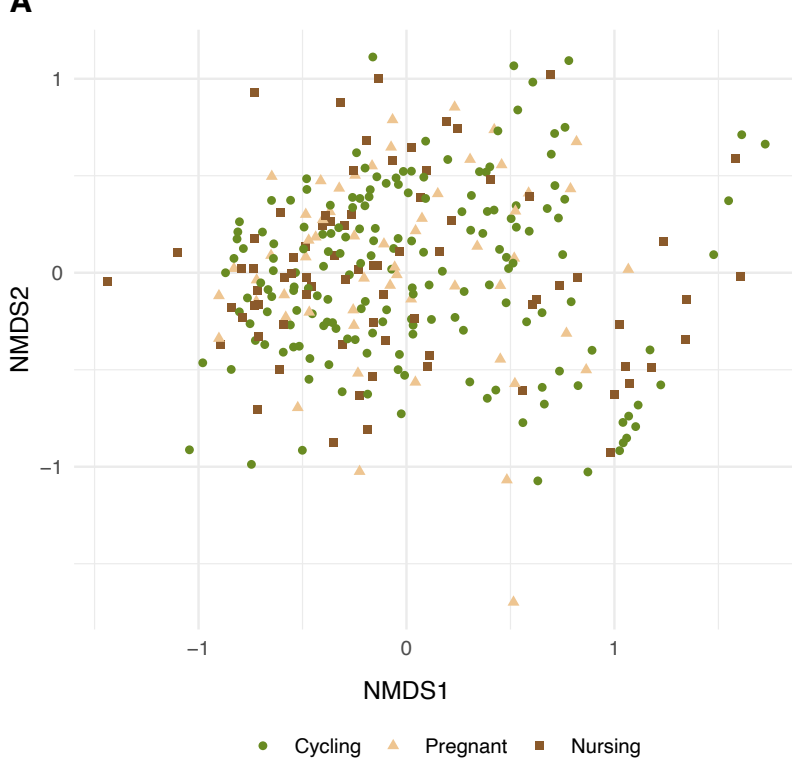

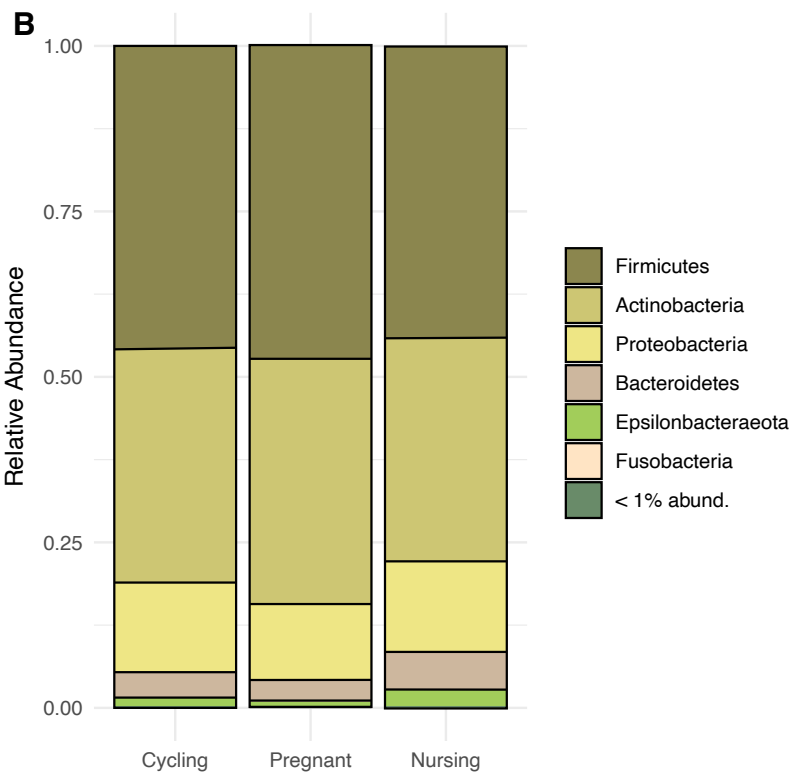

Figure 5. For each sample, Bray-Curtis dissimilarity values were computed and ordinated using non-metric multidimensional scaling (NMDS). Samples did not cluster according to reproductive status which was also not a significant predictor of dissimilarity among fecal microbial communities. Relative abundance of phyla were visualized across reproductive statuses. Phyla with relative abundances below 0.01 were grouped in the category " $<1 \%$ abund." Relative abundances remained generally stable across the reproductive states.

212 To investigate other structural changes in the fecal microbial communities among reproductive 213 states, we visualized the relative abundance of phyla across the reproductive cycle, grouping all 214 phyla with relative abundances lower than 1\% (Figure 5b). We found that pregnant females

215 exhibited a small but significant increase in Firmicutes taxa compared to cycling females $(\log 2$ 216 fold change $=0.493, \mathrm{SE}=0.146, \mathrm{P}=0.008)$. Cycling females exhibited a small but significant

217 increase in the phylum Epsilonbacteraeota ( $\log 2$ fold change $=1.149, \mathrm{SE}=0.293, \mathrm{P}<0.001)$.

218 We also examined whether specific genera were differentially abundant among the reproductive 219 states and found that cycling females exhibited a significant increase in taxa from the genus 
223 Reproductive status was a significant predictor of estimated metabolic pathway dissimilarity, but

224 the effect was small (PERMANOVA; $\mathrm{df}=2, \mathrm{~F}$ Value $=2.5075, \mathrm{R}^{2}=0.017, \mathrm{p}<0.001$ ). Nursing

225 females were characterized by a significant increase in pathways related to biotin metabolism

226 (Linear Discriminant Analysis; LDA Score $=3.176, \mathrm{p}=0.006$ ), but otherwise metabolic

227 pathways did not differ substantially between reproductive statuses.

\section{DISCUSSION}

We analyzed a robust set of $>13,000$ individual scans to explore behavioral responses to reproduction and 308 fecal samples to understand gut microbial community dynamics in

233 population of reproductively mature female capuchin monkeys. Our main findings are 1)

234 reproductive state explains some variation in activity budget; in particular, foraging decreases

235 significantly in early nursing compared to cycling, though resting and foraging activity remain

236 otherwise stable across the reproductive cycle; 2) reproductive state explains some variation in

237 gut microbial dissimilarity and relative abundance of putative metabolic pathways; 3 ) ecological

238 and social variables including maximum temperature, social dominance, and estimated fruit

239 biomass, as well as individual identity are related to activity and the gut microbiota more

240 strongly than reproductive status.

Activity budgets remain largely consistent within and among reproductive states

244 In our first aim we sought to compare activity budgets of white-faced capuchins among and

245 within cycling, pregnancy, and nursing states at a fine scale. Resting behavior was largely

246 consistent across the reproductive cycle, but the variation observed suggests that resting

247 increases slightly during pregnancy. This pattern fits well with expectations from available data

248 on energy expenditure. While no single stage in the reproductive cycle was stastically

249 significantly different from the other stages in terms of resting, we observed a general pattern

250 that suggests resting increases during pregnancy. Foraging behavior decreased steadily during

251 pregnancy, possibly in connection to resting increases. 
253 During nursing, resting behavior peaked in early nursing, before decreasing in mid-nursing, and 254 rebounding in late nursing. Foraging behavior decreased steadily into early nursing, where it was 255 significantly lower in early nursing compared to other stages. We recognize that proportion of 256 scans per day spent in foraging states is an imperfect estimator for amount of food consumed.

257 Nevertheless, the statistically significant drop in foraging behavior during early nursing may 258 have energy balance implications for females. Capuchins may alter behavior in other ways to 259 cope with changing energy needs. For example, past research on a small subset of the current 260 study population suggests that lactating females increase feeding rate (McCabe \& Fedigan,

261 2007), though we unfortunately lack the required depth of focal data to test this hypothesis in the 262 current data set. There might also be underlying metabolic or other physiological changes such 263 as metabolic shifts associated with energy sparing that we were not able to capture in the present 264 study that help pregnant and lactating females address energy costs. Even though our sample size 265 of 33 females tracked over multiple years and pregnancies is one of the largest available for wild 266 primates, the pattern we observed in the resting behavior may be too subtle to reach significance 267 with present sample sizes.

269 While capuchins are generally considered highly flexible and plastic in response to changes in 270 their environments (Fragaszy et al., 2004), it is likely that both resting and foraging behavior is 271 relatively constrained in this population and are influenced by social and environmental factors, 272 limiting the potential for flexibility in this domain in response to reproductive state. When food 273 and water resources change drastically from season to season, capuchins alter their foraging and 274 ranging behaviors to overlap with available food and water (Campos \& Fedigan, 2009). We also 275 see changes in thermoregulatory behaviors; capuchins rest more during the hottest parts of the 276 day in the hotter season of the year, and exhibit seasonal behaviors likely linked to 277 thermoregulation and water consumption. It is also possible that female capuchins are 278 constrained in altering activity budget due to the pressures associated with group living. White279 faced capuchins form cohesive groups, with the exception of emigrant males dispersing to non280 natal groups. Females remain the same social group their entire lives (with the rare exception of 281 group fissioning events), and capuchins forage, rest, and travel in close proximity to one another. 282 Pregnant and lactating females may theoretically benefit from resting for longer periods of the 
283 day or foraging for longer periods in a particularly productive food patch; however, if a pregnant

284 or lactating female acts independently of the larger social group, she may be increasing risk of

285 predation or encounters with other social groups. The ability of females to significantly alter

286 resting or foraging may be constrained by the behavioral choices in the rest of the social group.

287 Future studies examining these constraints on activity budget shifts represent an exciting future

288 avenue of behavioral research.

Gut microbial communities remain largely stable structurally and functionally throughout

291 reproduction

We found mixed support for the prediction that females modulate the gut microbiome to increase energy absorption from food during pregnancy and nursing. We did not observe statistically significant changes in alpha diversity in pregnant females, which contrast previous studies in humans that showed a drastic decrease in alpha diversity (Koren et al., 2012). Females in cycling, pregnant, and nursing states clustered separately in a beta diversity plot, but the effect was very small, suggesting alternative drivers of community dissimilarity, including individual variation. Overall, female capuchins did not exhibit large gut microbial structural shifts, but we did find that pregnant females exhibited small but significant increases in Firmicutes taxa. At a broad scale, taxa within Firmicutes break down carbohydrates that endogenous host enzymes are unable to metabolize. The ratio of Firmicutes to Bacteroidetes has previously been suggested as a biomarker for increased metabolic activity in the gut (Turnbaugh et al., 2006); however, contrasting reports of this ratio suggest it might not serve as a universal biomarker for increased energy (Magne et al., 2020). Further, the lack of substantial change in relative abundance among

306 bacterial genera in our samples suggest that, in this population, reproductive state is not a critical

307 driver of gut microbial community composition, at least at a broad scale.

309 Though gut microbial communities remained largely stable, nursing capuchins in our population

310 exhibited a significant increase in a biotin metabolism pathway in the gut. Endogenous enzymes

311 as well as gut microbes can metabolize biotin, which is involved in a broad range of metabolic

312 processes related to fat-, carbohydrate-, and amino acid-utilization in mammals. Biotin

313 deficiency and biotin excess during the reproductive has been linked to tetratogenic effects in 
314 pregnancy in mice and humans (Báez-Saldaña et al., 2009). Studies of humans have repeatedly

315 demonstrated that lactation and pregnancy alter biomarkers of biotin metabolism, and that

316 humans are typically deficient in biotin during pregnancy, though precise requirements of biotin

317 remain unknown (Mock et al., 2002; Perry et al., 2014). If non-human primates also require

318 increased biotin during gestation and lactation, our results suggest that the gut microbiome may

319 play an important role in helping nursing females increase biotin supplementation during fetal

320 growth and infant development.

322 Previous studies of non-human primates tend to suggest that the gut microbiome shifts

323 considerably throughout the reproductive cycle (Amato et al., 2014; Mallott et al., 2020; Mallott

$324 \&$ Amato, 2018). In a recent examination of white-faced capuchin reproductive microbial

325 ecology, Mallott and Amato (2018) examined how gut microbial communities changed across

326 reproductive states in females $\left(n_{\text {females }}=5, n_{\text {samples }}=39\right)$ sampled across one year in an

327 aseasonally breeding population of white-faced capuchins. The authors found evidence to

328 suggest that the gut microbiome shifts significantly during the reproductive cycle, including

329 differences in relative abundance of Firmicutes (lower in pregnant versus cycling females) and

330 Actinobacteria (higher in pregnant versus lactating females). Further, the authors found that

331 reproductive state was significantly associated with energy and glycan metabolism (Mallott \&

332 Amato, 2018). However, this capuchin population lives in a wet aseasonal forest, with little

333 variation in food and water availability throughout the annual cycle (Mallott et al., 2018). The

334 biome where our present study took place is, by contrast, highly seasonal, with distinct shifts in

335 temperature, water availability and fruit and arthropod abundance (Campos et al., 2015;

336 Mosdossy et al., 2015). In the hot, dry season animals contend with harsh drought and high

337 temperature, while in the rainier, cooler season, these forces are less present. We have observed

338 strong effects of seasonality on ranging behavior, activity budget, food choice, and the gut

339 microbiota in this population (Campos et al., 2014; Campos \& Fedigan, 2009; Melin et al., 2020;

340 Orkin et al., 2019; Orkin et al., 2019). Extreme seasonality at the present study site and

341 aseasonality at a different site that is home to the same species of capuchins may have critical

342 implications for our understanding of how flexible and plastic this species is across its home

343 range. 
345 Capuchins are generally thought of as one of the most flexible and generalist species of

346 platyrrhine primates that can thrive in a wide variety of habitats and that can consume a vast

347 diversity of food types (Fragaszy et al., 2004; Melin et al., 2020). However, the reality might be

348 a bit more nuanced. Steig Johnson and Kerry Brown (2018) examined niche breadth in

349 Mesoamerican primates using an ecological niche modeling approach, and found that capuchins

350 were considerably constrained by several ecological factors, including precipitation in particular

351 seasons, and seaonality of temperatures. The temperatures and water availability at our study site

352 near the limit of suitable conditions for this species, which may explain the lack of flexibility that

353 we see in behavior and gut microbiota in this population. Understanding how flexibility shifts

354 across a species range and identifying what ecological factors permit or constrain a species'

355 ability to be flexible, is critical to understand not only that species' history, but also how it might

356 fare as ecosystems face anthropogenic and climate-related changes.

Alternatively, we may be missing the importance of individual variation in response to reproductive states. For example, humans residing in the same population display remarkable differences in response to reproductive demands across our global range; for example, women in the Gambia and Sweden experience high within-group variation in weight gain and energy expenditure throughout pregnancy (Poppitt et al., 1993, 1994) and high inter-individual gut microbiota among members of the same population has been found in humans (Healey et al., 2017; Zhu et al., 2015). We found that individual identity accounted for a significant amount of gut microbial community dissimilarity, which raises exciting questions about individual strategies for coping with reproduction. Further, while activity budgets and amplicon sequencing

367 provide important, thought relatively coarse, data about behavior and gut microbiota

368 respectively, future research on this population of capuchin could incorporate individual focal

369 data and/or shotgun metagenomic sequencing, both of which would provide a more detailed

370 understanding of capuchin reproductive behavioral and microbial ecology.

372 How animals respond to the demands of reproduction has important consequences for the 373 viability of offspring, and on a longer term scale, the fitness of a population or species. The 374 intricacies of how animals are able to shift their behavior and how their gut microbial 375 communities may respond to pregnancy and lactation represent a complex but critical area of 
research. For populations living near the ecological limits of their species ranges, it is especially important to understand the extent to which plasticity in behavior and gut microbial communities might influence pregnancy outcomes and multi-generational fitness.

\section{MATERIALS AND METHODS}

Field site \& study population

384 We collected samples and behavioral data at Sector Santa Rosa (SSR), located in the Área de

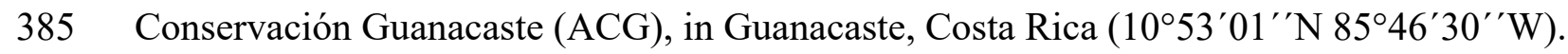

386 Sector Santa Rosa is a mosaic of forest types, including tropical dry forest and small patches of 387 older growth evergreen forest. The ACG experiences two distinct seasons: a hot, dry period from 388 late November to mid-May and a cooler, rainy period for the remainder of the year, during which almost all of the annual rainfall (900 mm-2400 mm) occurs (Melin et al., 2020). Fruit abundance varies throughout the year and estimates of fruit biomass are calculated monthly (Campos et al., 2015; Orkin et al., 2019).

The study population of white-faced capuchin monkeys has been continuously monitored non-

394 invasively since 1983. Female capuchins are philopatric and reach reproductive maturity by 6 395 years of age. Births are moderately seasonal at Sector Santa Rosa, with 44\% of births occurring 396 between May and July each year (Carnegie et al., 2011). Gestation is 157 +/- 8 days and typical 397 inter-birth intervals are 2.5 years (Melin et al., 2020). Lactation lasts for approximately 12 398 months; in early lactation, infants are almost exclusively dependent on their mothers and are 399 observed nursing frequently (Fragaszy et al., 2004). It should be noted that in other white-faced 400 capuchin populations, the lactation phase can extend to 23 months (Melin et al., 2020). After the 401 first three months of nursing, infants gradually learn to forage independently and incorporate 402 non-milk foods into their diet. By 12 months of age, infants are rarely observed nursing or 403 traveling dorsally on their mothers. Infant capuchins are occasionally observed nursing from 404 adult females that are not their mothers (Sargeant et al., 2016). 
406 We collected data across 5 years (2014-2018). Non-invasive fecal samples were collected from

40733 adult females from 4 social groups during multiple sampling bouts in 2014-2016. We

408 collected behavioral data from 33 adult females from 4 social groups during multiple sampling

409 bouts in 2016-2018. One female from the 2014-2016 fecal sampling periods disappeared from

410 the population and was not included in behavioral analysis but was included in gut microbiome

411 analysis. Two females reached sexual maturity during the 2016-2018 period and were included

412 in behavioral analysis but not in gut microbiome analysis. All animals in the study population are

413 habituated to researcher presence and individually identifiable through physical markings on the

414 face and body. In our dataset, 2016 was the only year in which we collected behavioral records

415 and fecal samples simultaneously. Ideally, we would have behavioral records and fecal samples

416 for all 5 years, but this was not possible due to field and laboratory limitations. However, the

417 nearly all individuals (31/33) were present across the entire study period and each dataset

418 (behavioral and fecal) is robust and overlapping.

420 During bi-monthly censuses at the field site, reproductive state of each female is recorded.

421 Pregnancies during the study period were determined via protrusion of the abdomen (visible

422 approximately 8 weeks after conception), and after infant were born we estimated conception

423 dates using 157 days as gestation length. At 15 time points throughout the 5-year study, females

424 exhibited protruding abdomens consistent with pregnancy, but then were later observed with flat

425 abdomens. We characterised these instances as pregnancy lsos, though we do not have hormonal

426 data to confirm these pregnancies, which is a limitation associated with this assumption. We

427 determined nursing on an libitum basis through observations of young monkeys suckling from

428 adult females. Following Bergstrom (2015), we considered females nursing their own infants

$429<12$ months of age to be lactating. Juvenile capuchins are occasionally observed suckling after

43012 months of age, but it is difficult to determine whether milk is transferred. We did not consider

431 cases in which juveniles $>12$ months were suckling to be indicative of lactation in the adult

432 females from whom they were attempting to nurse. We considered females that were never

433 observed as nursing or pregnant on data collection days as non-pregnant, non-nursing. We

434 grouped all non-pregnant, non-nursing females into the category "cycling" following Bergstrom

435 (Bergstrom, 2015). 
437 Studies of humans and non-human primates suggest that energy requirements change throughout

438 pregnancy and lactation (Emery Thompson, 2013). To examine differences that occur within

439 each reproductive state, we subset the reproductive states into stages: Cycling (Pre-conception),

440 Pregnancy Stage 1 (early), Pregnancy Stage 2 (mid), Pregnancy Stage 3 (late), Nursing Stage 1

441 (early), Nursing Stage 2 (mid), Nursing Stage 3 (late), and Cycling (Post-weaning) (Table 1).

443 Table 1. Pregnancy and nursing were divided into three equal stages. Cycling (Pre-conception)

444 consisted of 60 days prior to a conceptive event, and Cycling (Post-weaning) consisted of 60

445 days post-weaning.

\section{Reproductive State}

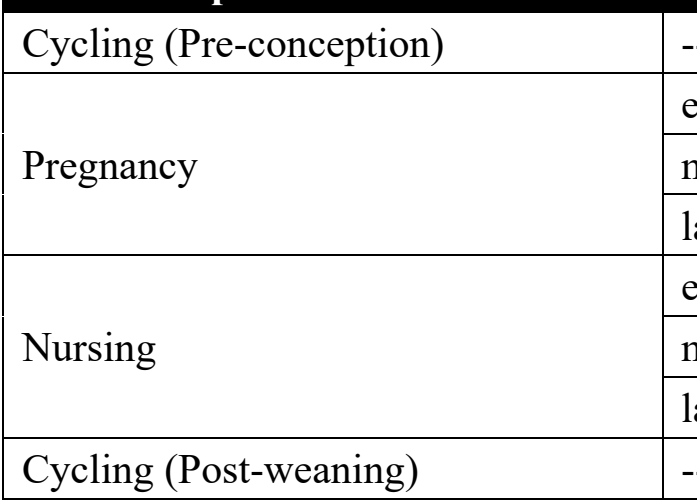

\section{Stage}

Length

60-0 days before conception 0-53 days post conception 54-104 days post conception 105-158 days post conception 0-121 days postpartum 122-242 days postpartum 243-365 days postpartum 0-60 days post weaning

448 The reproductive state of each of the 33 adult female capuchins is presented in Figure 6.

449 Throughout the 2014-2018 study period, 43 infants were born in the study population.

450 Behavioral data collection periods (2016-2018) included portions of or the full duration of 40 of

451 these pregnancies. Of these 40 infants, 26 infants survived to weaning (365 days), and behavioral 452 data collection included portions of all 40 nursing periods and captured transitions from nursing 453 to non-nursing states. 


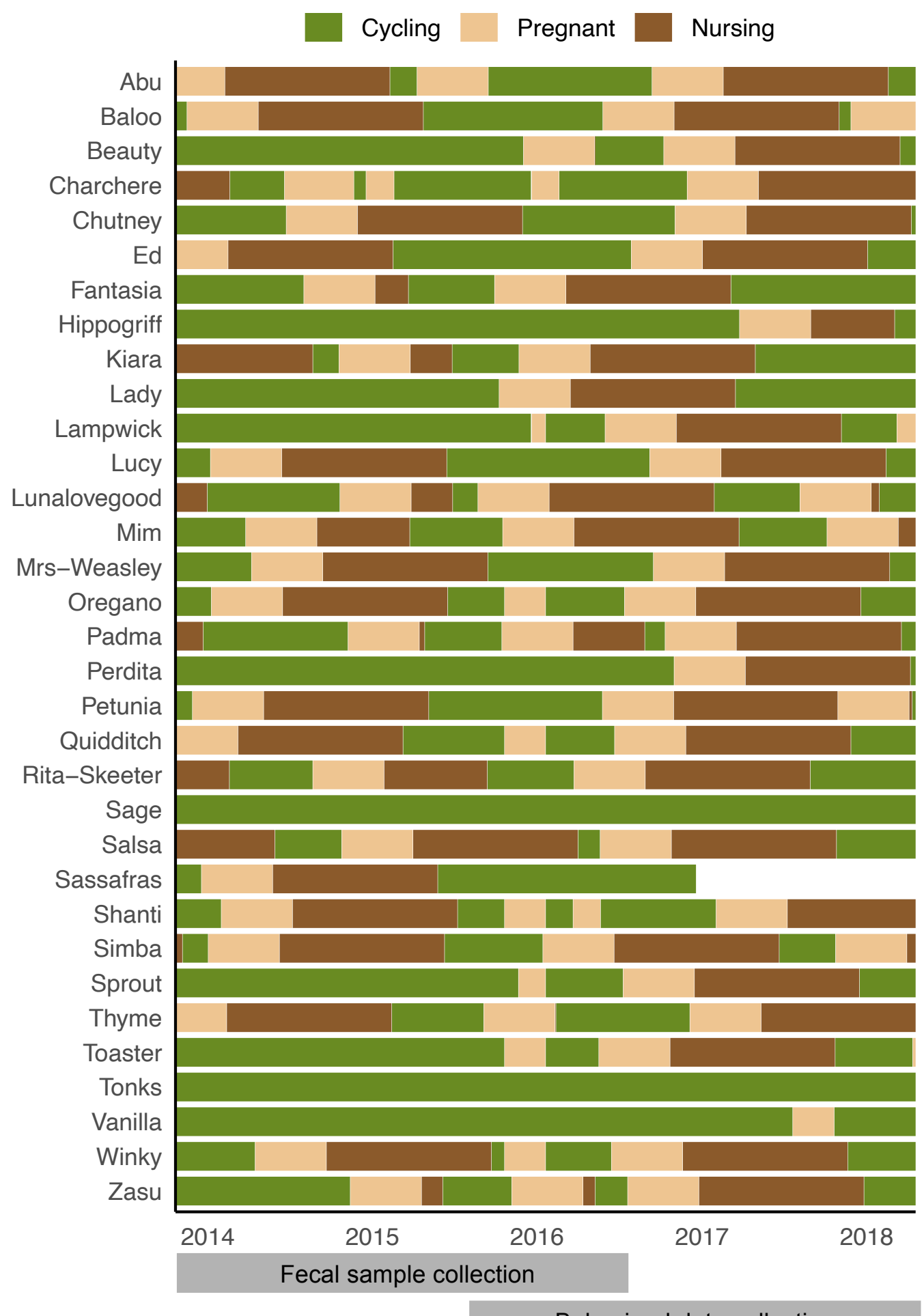

Behavioral data collection

456 Figure 6. Reproductive status of study individuals observed between April 1, 2014 and June 30, 457 2018. Fecal samples were collected between April 29, 2014 and September 27, 2016. Behavioral 
data were collected between April 20, 2016 and June 22, 2018. One individual (Sassafras) disappeared from the population in early 2017. Two individuals (Tonks and Vanilla) reached reproductive maturity during the study, but were never observed to be pregnant. Multiple females were observed to be pregnant via protrusion of the abdomen, but were subsequently observed with no protrusion. In these cases the tan (pregnancy) segments are followed by green (cycling) and not by brown (nursing) segments. Nursing segments that are shorter than 12 months represent cases where infants died.

To determine daily activity budgets, we followed each of the 4 social groups from dawn (05:30) until dusk (18:00) for 4-6 days per month. Individual scans were recorded every 30 minutes on the hour and half hour. During a 10-minute period, we recorded the behavioral state of each individual in the group using an established ethogram (Supplemental Table 1). We chose to use scan sampling instead of focal sampling to determine individual activity budgets because it allows for more evenly distributed data across all individuals, season, and time of day (De

474 Ruiter, 1986; Melin et al., 2018). Inter-observer reliability was tested daily for the first 4 weeks 475 of each sampling period, then weekly or biweekly for the remainder of each period. We collected 47613721 individual scans over the course of 222 contact days.

\section{Behavioral models for activity budget analysis}

We fit two generalized linear mixed models (GLMMs) that included reproductive stage as our predictor of interest. For our Resting Model, number of resting scans per day was our response variable, while for our Foraging Model, number of foraging scans per day was our response variable. In each model, we included monkey dominance category, daily maximum temperature

$484\left({ }^{\circ} \mathrm{C}\right)$, daily rainfall $(\mathrm{cm})$, and mean monthly estimated fruit biomass $(\mathrm{kg} / \mathrm{ha})$ as predictor variables as they may influence activity in this population. Ecological variables (e.g. maximum temperature, rainfall, and fruit biomass) were $z$-transformed (i.e. scaled so that each had a mean

487 of 0 and standard deviation of 1) to stabilize the models. We included individual animal identity as a random effect in all models. Sampling effort (i.e. number of scans per animal per rotation) 
varied due to changing field conditions and stochastic movement and dispersal of group members. We included a log-transformed offset of total scans per animal per day to account for differences in sampling effort. Because our behavioral data are count data and because

492 behavioral scans occur independently, a Poisson distribution with a logit link was designated in 493 all models.

We tested whether our alternative models (fixed and random effects) outperformed the null models (random effects only). Likelihood ratio tests were conducted using the $\mathrm{R}$ function ANOVA. To test for multicollinearity between ecological variables a generalized linear model (GLM) was created to determine the variance inflation factor (VIF) (Craney \& Surles, 2002). These models were identical to the alternative models above but contained only fixed effects. The resulting VIF measures collinearity in fixed effects. Craney and Surles (2002) suggest that appropriate cutoffs for VIF range from 5-10. All ecological variables had VIF indices below 2.0 and were kept in all models (Supplemental Table 4).

We computed incidence rate ratios using the outputs of our GLMMs to examine the effects of each predictor variable. For categorical variables, the incidence rate ratios represent the ratio of the number of scans recorded in one level compared to the number of scans recorded in another level. For variables with multiple levels (e.g. reproductive stage, dominance), a reference level is selected and other levels are compared to the reference level to contextualise the effects of each level on the response variable - in our case, resting scans or foraging scans. We plotted the predicted outcomes for each reproductive stage using the plot_model function in the R package

511 sjPlot (Lüdecke, 2021). Visualising our data this way allowed us to identify patterns of resting

512 behavior or foraging behavior associated with reproductive stage while holding constant the

513 effect of all other predictors in our models.

Fecal sampling for gut microbiota analysis

517 We collected fresh fecal samples from study individuals 1-2 times per month within each 518 sampling period in 2014-2016. Once an animal defecated, we immediately collected the feces into a sterile $2 \mathrm{~mL}$ cryovial using personal protective equipment to minimize human 
contamination of the samples. Fecal samples were visually inspected for dietary components,

521 many of which are identifiable by seed shape or arthropod exoskeletons remnants in the feces.

522 Dietary components were recorded to the most specific taxonomic classification possible.

523 Samples were stored on ice in insulated field packs for a maximum of 5 hours before being

524 transferred to a liquid nitrogen shipper (-90 C) for the remainder of the field season. If a sample

525 was suspected to be contaminated or compromised (e.g. falling on an area where a previous

526 defecation occurred), it was not collected. At the conclusion of each sampling season, samples

527 were shipped to the University of Calgary for processing. Samples were collected with

528 permission from the government of Costa Rica from CONAGEBIO (Approval No. R-025-2014-

529 OT-CONEGABIO) and exported under the Área de Conservación Guanacaste permit (DSVS-

530 029-2014-ACG-PI-060-2014). Samples were imported into Canada with permission from the

531 Canadian Food Inspection Agency (Import Permit: A-2016-03992-4). All data collection

532 complied with Costa Rican law and were approved by University of Calgary Animal Care

533 Committee (\#AC15-0161).

Laboratory processing

Prior to DNA extractions, all laboratory equipment was bleached, autoclaved, and exposed to 60 minutes under UV light to minimize laboratory contamination. We randomized the order in which samples were extracted to decrease bias associated with batch effects. Prior to DNA

540 extraction, we split each sample into two tubes, Extraction A and Extraction B to decrease

541 potential bias based on stochastic distribution of microbes within a fecal. During each round of

542 extractions, we extracted a laboratory blank to control for contamination from laboratory

543 surfaces or reagent. The extraction protocol included a bead-beading step to increase DNA yield

544 and specific optimizations are described in Orkin et al. (2019). We purified extracted DNA using 545 an Invitrogen PureLink PCR Purification kit (ThermoFisher Scientific Part No. K310001), after

546 which we combined extractions A and B prior to library preparation. Illumina amplicon

547 sequencing libraries were prepared in for the V4 region of the 16S rRNA gene at the University 548 of Minnesota following Gohl et al. (2016). Libraries were sequenced twice at the University of

549 Calgary to increase reads per sample on an Illumina MiSeq using v2 chemistry. 
Raw reads were demultiplexed and sequencing barcodes and indices were removed using cutadapt (Martin, 2011). We removed ambiguous base calls using the filterAndTrim function in the R package DADA2, removed locus-specific primers using cutadapt, then determined quality profiles using the plotQualityProfile (Callahan et al., 2016). Poor quality bases were truncated again using the filterAndTrim function. Error rates were learned and dereplication was done using learnErrors and derepFASTQ functions respectively. We merged forward and reverse reads to generate amplicon sequence variants (ASVs). Chimeras were removed using the removeBimeraDenovo function in DADA2, and we assigned taxonomies to ASVs using the silva_nr_v132_train_set.fa file. We extracted and sequenced a series of negative lab controls, which were then used to detect potential contaminants in the program decontam (Davis et al., 2018). Using the function isContaminant, we compared the prevalence of sequences from the negative controls with sequences from our samples. Using a 50\% probability threshold, we identified probable contaminants and removed them from our fecal sample sequences. We then removed uncharacterized phyla, chloroplasts, and mitochondrial sequences from the dataset.

\section{Gut microbiota community structure}

To explore shifts in gut microbial community structure throughout the reproductive cycle, we computed Chao species richness and Shannon alpha diversity for each sample. We removed 4 samples with Chao1 richness values $>400$ that were distinctly different that the remaining 304 samples, with Chao1 values ranging from 12-385. Because we sampled individuals multiple

574 times, and because sampling effort across individuals was uneven, we fit linear mixed effects models to examine the relationship between reproductive state and richness and diversity metrics. We included individual identity as a random effect in both models and included rainfall

577 and maximum temperature as ecological predictors. We used an alpha of 0.05 as a significance cut-off.

We then removed extremely low-prevalence phyla for the remainder of analysis and filtered out taxa that were not present in at least $5 \%$ of samples. Due to sample size constraints, we were not 
582 able to divide fecal samples into subsets within reproductive states and therefore proceeded with

583 the categories cycling, pregnant, and nursing. To explore the relationship between reproductive

584 state and gut microbial community dissimilarity within our sample set, we transformed sample

585 counts to relative abundances and then computed Bray-Curtis dissimilarity values using the

586 ordinate function in phyloseq. We visualized beta diversity using non-metric multidimentional

587 scaling (NMDS). We used the function adonis in the R package vegan to run a PERMANOVA

588 to examine predictors of Bray-Curtis dissimilarities in our dataset (Dixon, 2003). In this

589 PERMANOVA, we included reproductive status as our predictor of interest, as well as

590 individual identity, rainfall, and dietary category based on fecal contents, as we suspected these

591 could be related to microbial community dissimilarity.

\section{Differential abundance}

To examine which, if any, bacterial taxa were differentially abundant among reproductive states, we agglomerated samples at the genus level, then used the R package DESeq 2 to compute variance stabilized counts (Love et al., 2014). We then used Wald tests to determine the log2 fold differences among the reproductive states and used adjusted $P$ values (alpha $=0.01)$ to

599 account for multiple tests. We conducted pairwise comparisons between cycling and pregnant

600 females, pregnant and nursing females, and nursing and cycling females to examine how these

601 transitions might be related to gut microbial community structure. We repeated this analysis for

602 all bacterial phyla in our dataset to examine courser scale shifts in fecal microbial community

603 structure among reproductive states.

Estimated metabolic pathways

607 We used the package PICRUSt2 to estimate metabolic pathways present in our samples using 608 KEGG orthologs (Douglas et al., 2020). We tested for significant dissimilarity in estimated 609 metabolic pathways among the reproductive states using a PERMANOVA including individual 610 identity as a control. We then used the linear discriminant analysis (LDA) effect size method 611 using the LEfSe package (Segata et al., 2011), which identifies the functional metabolic 612 pathways likely to explain differences between reproductive states and stages in our data. We 
613 used a logarithmic LDA score of 2 as a cut off for discrimant features, and individual identity

614 was included as a predictor to account for individual variation. All code used for analysis in this

615 study is available at

616 https:/github.com/webbshasta/CapuchinReproductionBehaviourMicrobiome.

\section{ACKNOWLEDGEMENTS}

619 We thank: Roger Blanco and the Área de Conservación Guanacaste for permitting this research;

620 Saul Cheves Hernandez, Monica Myers, Kelly Kries, Nuria Ferrero, Nile Carrethers, and Ronald

621 Lopez for assistance in the field; and Urs Kalbitzer and Jeremy Hogan for help with analyses.

622 The project that gave rise to these results received the support of a fellowship from "la Caixa"

623 Foundation (ID 100010434) and from the European Union's Horizon 2020 research and

624 innovation programme under the Marie Skłodowska-Curie grant agreement No 847648 (JDO).

625 The fellowship code is LCF/BQ/PI20/11760004. Research was also supported by The Eppley

626 Foundation for Research (JDO, ADM), The International Center for Advanced Renewable

627 Energy and Sustainability (I-CARES) (JDO, ADM), Washington University in St. Louis (JDO,

628 ADM), the Alberta Children's Hospital Research Institute (ACHRI) (ADM, SEW, JDO), the

629 National Sciences and Engineering Research Council (ADM), a Canada Research Chair Tier II

630 (ADM), Sigma Xi The Scientific Honor Research Society (SEW), the American Society of

631 Primatologists (SEW), Alberta Innovates Technology Futures (SEW), and a Vanier Canada

632 Graduate Scholarship (SEW).

\section{COMPETING INTERESTS}

634 The authors declare no competing interests.

\section{REFERENCES}

637 Altmann, J. (2001). Baboon Mothers and Infants. University of Chicago Press.

638 Amato, K. R., Leigh, S. R., Kent, A., Mackie, R. I., Yeoman, C. J., Stumpf, R. M., Wilson, B. 

satisfying the nutritional demands of adult and juvenile wild, black howler monkeys (Alouatta pigra). American Journal of Physical Anthropology, 155(4), 652-664.

642

644

645

646

Báez-Saldaña, A., Camacho-Arroyo, I., Espinosa-Aguirre, J. J., Neri-Gómez, T., Rojas-Ochoa, A., Guerra-Araiza, C., Larrieta, E., Vital, P., Díaz, G., Chavira, R., \& Fernandez-Mejia, C. (2009). Biotin deficiency and biotin excess: Effects on the female reproductive system. Steroids, 74(10), 863-869. https://doi.org/10.1016/j.steroids.2009.06.004

Bergstrom, M. L. (2015). Seasonal Effects on the Nutrition and Energetic Condition of Female White-Faced Capuchin Monkeys [Doctoral dissertation]. University of Calgary.

Bowen, W. D., Ellis, S. L., Iverson, S. J., \& Boness, D. J. (2001). Maternal effects on offspring growth rate and weaning mass in harbour seals. Canadian Journal of Zoology, 79(6), 1088-1101.

Callahan, B. J., McMurdie, P. J., Rosen, M. J., Han, A. W., Johnson, A. J. A., \& Holmes, S. P. (2016). DADA2: High-resolution sample inference from Illumina amplicon data. Nature Methods, 13(7), 581-583. https://doi.org/10.1038/nmeth.3869

Campos, F. A., Bergstrom, M. L., Childers, A., Hogan, J. D., Jack, K. M., Melin, A. D., Mosdossy, K. N., Myers, M. S., Parr, N. A., Sargeant, E., Schoof, V. A. M., \& Fedigan, L. M. (2014). Drivers of home range characteristics across spatiotemporal scales in a Neotropical primate, Cebus capucinus. Animal Behaviour, 91, 93-109. https://doi.org/10.1016/j.anbehav.2014.03.007

Campos, F. A., \& Fedigan, L. M. (2009). Behavioral adaptations to heat stress and water scarcity in white-faced capuchins (Cebus capucinus) in Santa Rosa National Park, Costa Rica. American Journal of Physical Anthropology, 138(1), 101-111. 
662 Campos, F. A., Jack, K. M., \& Fedigan, L. M. (2015). Climate oscillations and conservation measures regulate white-faced capuchin population growth and demography in a regenerating tropical dry forest in Costa Rica. Biological Conservation, 186, 204-213.

665 Carnegie, S., Fedigan, L., \& Melin, A. (2011). Reproductive Seasonality in Female Capuchins (Cebus capucinus) in Santa Rosa (Area de Conservación Guanacaste), Costa Rica. International Journal of Primatology, 32(5), 1076-1090. afh.

Clutton-Brock, T. H., Albon, S. D., \& Guinness, F. E. (1989). Fitness costs of gestation and lactation in wild mammals. Nature, 337(6204), 260-262. https://doi.org/10.1038/337260a0

672 Craney, T. A., \& Surles, J. G. (2002). Model-Dependent Variance Inflation Factor Cutoff Values. Quality Engineering, 14(3), 391-403. https://doi.org/10.1081/QEN-120001878

674 Davis, N. M., Proctor, D. M., Holmes, S. P., Relman, D. A., \& Callahan, B. J. (2018). Simple statistical identification and removal of contaminant sequences in marker-gene and metagenomics data. Microbiome, 6(1), 226. https://doi.org/10.1186/s40168-018-0605-2

De Ruiter, J. R. (1986). The influence of group size on predator scanning and foraging behaviour of wedgecapped capuchin monkeys (Cebus olivaceus). Behaviour, 98(1), 240-258.

679 Deschner, T., Kratzsch, J., \& Hohmann, G. (2008). Urinary C-peptide as a method for monitoring body mass changes in captive bonobos (Pan paniscus). Hormones and Behavior, 54(5), 620-626. https://doi.org/10.1016/j.yhbeh.2008.06.005 
DiGiulio, D. B., Callahan, B. J., McMurdie, P. J., Costello, E. K., Lyell, D. J., Robaczewska, A., Sun, C. L., Goltsman, D. S. A., Wong, R. J., Shaw, G., Stevenson, D. K., Holmes, S. P., \& Relman, D. A. (2015). Temporal and spatial variation of the human microbiota during pregnancy. Proceedings of the National Academy of Sciences, 112(35), 11060-11065. https://doi.org/10.1073/pnas.1502875112

Dixon, P. (2003). VEGAN, a package of R functions for community ecology. Journal of Vegetation Science, 14(6), 927-930. https://doi.org/10.1111/j.1654-1103.2003.tb02228.x

Douglas, G. M., Maffei, V. J., Zaneveld, J. R., Yurgel, S. N., Brown, J. R., Taylor, C. M., Huttenhower, C., \& Langille, M. G. I. (2020). PICRUSt2 for prediction of metagenome functions. Nature Biotechnology, 38(6), 685-688. https://doi.org/10.1038/s41587-0200548-6

Dufour, D. 1., \& Sauther, M. 1. (2002). Comparative and evolutionary dimensions of the energetics of human pregnancy and lactation. American Journal of Human Biology, 14(5), 584-602. https://doi.org/10.1002/ajhb.10071

Edwards, S. M., Cunningham, S. A., Dunlop, A. L., \& Corwin, E. J. (2017). The Maternal Gut Microbiome during Pregnancy. MCN. The American Journal of Maternal Child Nursing, 42(6), 310-317. https://doi.org/10.1097/NMC.0000000000000372

Ellison, P. T. (2003). Energetics and reproductive effort. American Journal of Human Biology, 15(3), 342-351. https://doi.org/10.1002/ajhb.10152

Emery Thompson, M. (2013). Comparative reproductive energetics of human and nonhuman primates. Annual Review of Anthropology, 42, 287-304. 
Fontaine, E. (2012). Food Intake and Nutrition During Pregnancy, Lactation and Weaning in the Dam and Offspring. Reproduction in Domestic Animals, 47(s6), 326-330. https://doi.org/10.1111/rda.12102

Fragaszy, D. M., Visalberghi, E., \& Fedigan, L. M. (2004). The Complete Capuchin: The Biology of the Genus Cebus. Cambridge University Press.

Gittleman, J. L., \& Thompson, S. D. (1988). Energy Allocation in Mammalian Reproduction. Integrative and Comparative Biology, 28(3), 863-875.

Gohl, D. M., Vangay, P., Garbe, J., MacLean, A., Hauge, A., Becker, A., Gould, T. J., Clayton, J. B., Johnson, T. J., Hunter, R., Knights, D., \& Beckman, K. B. (2016). Systematic

Harrison, M. J. (1983). Age and sex differences in the diet and feeding strategies of the green studies. Nature Biotechnology, 34(9), 942-949. https://doi.org/10.1038/nbt.3601

Healey, G. R., Murphy, R., Brough, L., Butts, C. A., \& Coad, J. (2017). Interindividual variability in gut microbiota and host response to dietary interventions. Nutrition Reviews, 75(12), 1059-1080. https://doi.org/10.1093/nutrit/nux062 Models to Compare Niche Breadth in Mesoamerican Primates. In U. Kalbitzer \& K. M. Jack (Eds.), Primate Life Histories, Sex Roles, and Adaptability: Essays in Honour of Linda M. Fedigan (pp. 311-329). Springer International Publishing. https://doi.org/10.1007/978-3-319-98285-4_15 
727 Jost, T., Lacroix, C., Braegger, C., \& Chassard, C. (2013). Stability of the Maternal Gut Microbiota During Late Pregnancy and Early Lactation. Current Microbiology, 68(4), 419-427. https://doi.org/10.1007/s00284-013-0491-6

730 Key, C., \& Ross, C. (1999). Sex differences in energy expenditure in non-human primates. Proceedings of the Royal Society of London B: Biological Sciences, 266(1437), 24792485. https://doi.org/10.1098/rspb.1999.0949

733 Koren, O., Goodrich, J. K., Cullender, T. C., Spor, A., Laitinen, K., Kling Bäckhed, H., Gonzalez, A., Werner, J. J., Angenent, L. T., Knight, R., Bäckhed, F., Isolauri, E., Salminen, S., \& Ley, R. E. (2012). Host Remodeling of the Gut Microbiome and Metabolic Changes during Pregnancy. Cell, 150(3), 470-480.

Love, M. I., Huber, W., \& Anders, S. (2014). Moderated estimation of fold change and dispersion for RNA-seq data with DESeq2. Genome Biology, 15(12), 550.

741 Lunn, P. G., Austin, S., Prentice, A. M., \& Whitehead, R. G. (1984). The effect of improved nutrition on plasma prolactin concentrations and postpartum infertility in lactating

745 Magne, F., Gotteland, M., Gauthier, L., Zazueta, A., Pesoa, S., Navarrete, P., \& Balamurugan, R. Gambian women. The American Journal of Clinical Nutrition, 39(2), 227-235. (2020). The Firmicutes/Bacteroidetes Ratio: A Relevant Marker of Gut Dysbiosis in Obese Patients? Nutrients, 12(5), 1474. https://doi.org/10.3390/nu12051474 
Mallott, E. K., \& Amato, K. R. (2018). The microbial reproductive ecology of white-faced capuchins (Cebus capucinus). American Journal of Primatology, 80(8), e22896. https://doi.org/10.1002/ajp.22896

Mallott, E. K., Amato, K. R., Garber, P. A., \& Malhi, R. S. (2018). Influence of fruit and invertebrate consumption on the gut microbiota of wild white-faced capuchins (Cebus capucinus). American Journal of Physical Anthropology, 165(3), 576-588. https://doi.org/10.1002/ajpa.23395

Mallott, E. K., Borries, C., Koenig, A., Amato, K. R., \& Lu, A. (2020). Reproductive hormones mediate changes in the gut microbiome during pregnancy and lactation in Phayre's leaf monkeys. Scientific Reports, 10(1), 9961. https://doi.org/10.1038/s41598-020-66865-2

Martin, M. (2011). Cutadapt removes adapter sequences from high-throughput sequencing reads.

McCabe, G. M., \& Fedigan, L. M. (2007). Effects of Reproductive Status on Energy Intake, Ingestion Rates, and Dietary Composition of Female Cebus capucinus at Santa Rosa, Costa Rica. International Journal of Primatology, 28(4), 837-851. afh.

764 Melin, A. D., Hogan, J. D., Campos, F. A., Wikberg, E., King-Bailey, G., Webb, S., Kalbitzer, 765 U., Asensio, N., Murillo-Chacon, E., Hernandez, S. C., Chavarria, A. G., Schaffner, C. 766 M., Kawamura, S., Aureli, F., Fedigan, L., \& Jack, K. M. (2020). Primate life history, 767 social dynamics, ecology, and conservation: Contributions from long-term research in 768 Área de Conservación Guanacaste, Costa Rica. Biotropica, 52(6), 1041-1064. https://doi.org/10.1111/btp.12867 
Melin, A. D., Webb, S. E., Williamson, R. E., \& Chiou, K. L. (2018). Data Collection in Field

771

772

773

774

775

776

777

778

779

780

781

782

783

784

785

786

787

788

789

790

791

Primatology: A Renewed Look at Measuring Foraging Behaviour. In U. Kalbitzer \& K. M. Jack (Eds.), Primate Life Histories, Sex Roles, and Adaptability: Essays in Honour of Linda M. Fedigan (pp. 161-192). Springer International Publishing. https://doi.org/10.1007/978-3-319-98285-4_9

Mock, D. M., Quirk, J. G., \& Mock, N. I. (2002). Marginal biotin deficiency during normal pregnancy. The American Journal of Clinical Nutrition, 75(2), 295-299. https://doi.org/10.1093/ajcn/75.2.295

Mosdossy, K. N., Melin, A. D., \& Fedigan, L. M. (2015). Quantifying seasonal fallback on invertebrates, pith, and bromeliad leaves by white-faced capuchin monkeys (Cebus capucinus) in a tropical dry forest. American Journal of Physical Anthropology, 158(1), $67-77$.

National Research Council, C. on A. N. (2003). Protein. In Read "Nutrient Requirements of Nonhuman Primates: Second Revised Edition” at NAP.edu (2nd ed., pp. 75-81). National Academies Press. https://doi.org/10.17226/9826

Orkin, J. D., Campos, F. A., Myers, M. S., Hernandez, S. E. C., Guadamuz, A., \& Melin, A. D. (2019). Seasonality of the gut microbiota of free-ranging white-faced capuchins in a tropical dry forest. The ISME Journal, 13(1), 183. https://doi.org/10.1038/s41396-0180256-0

Orkin, J. D., Webb, S. E., \& Melin, A. D. (2019). Small to modest impact of social group on the gut microbiome of wild Costa Rican capuchins in a seasonal forest. American Journal of Primatology, 81(11), e22985. https://doi.org/10.1002/ajp.22985 
Perry, C. A., West, A. A., Gayle, A., Lucas, L. K., Yan, J., Jiang, X., Malysheva, O., \& Caudill, M. A. (2014). Pregnancy and Lactation Alter Biomarkers of Biotin Metabolism in Women Consuming a Controlled Diet. The Journal of Nutrition, 144(12), 1977-1984.

Poppitt, S. D., Prentice, A. M., Goldberg, G. R., \& Whitehead, R. G. (1994). Energy-sparing strategies to protect human fetal growth. American Journal of Obstetrics and

Poppitt, S. D., Prentice, A. M., Jéquier, E., Schutz, Y., \& Whitehead, R. G. (1993). Evidence of energy sparing in Gambian women during pregnancy: A longitudinal study using wholebody calorimetry. The American Journal of Clinical Nutrition, 57(3), 353-364.

Sargeant, E. J., Wikberg, E. C., Kawamura, S., Jack, K. M., \& Fedigan, L. M. (2016). Paternal kin recognition and infant care in white-faced capuchins (Cebus capucinus). American Journal of Primatology, 78(6), 659-668. https://doi.org/10.1002/ajp.22530

Segata, N., Izard, J., Waldron, L., Gevers, D., Miropolsky, L., Garrett, W. S., \& Huttenhower, C. (2011). Metagenomic biomarker discovery and explanation. Genome Biology, 12(6), R60. https://doi.org/10.1186/gb-2011-12-6-r60 the diet of Alouatta palliata mexicana females in different reproductive states. Zoo Biology, 18(6), 507-513. https://doi.org/10.1002/(SICI)1098-2361(1999)18:6<507::AID$\mathrm{ZOO} 5>3.0 . \mathrm{CO} ; 2-\mathrm{R}$

Smid, M. C., Ricks, N. M., Panzer, A., Mccoy, A. N., Azcarate-Peril, M. A., Keku, T. O., \& Boggess, K. A. (2018). Maternal gut microbiome biodiversity in pregnancy. American Journal of Perinatology, 35(1), 24-30. https://doi.org/10.1055/s-0037-1604412 
815 Sun, B., Xu, X., Xia, Y., Cheng, Y., Mao, S., Xiang, X., Xia, D., Wang, X., \& Li, J. (2021).

816 Variation of Gut Microbiome in Free-Ranging Female Tibetan Macaques (Macaca thibetana) across Different Reproductive States. Animals, 11(1), 39. https://doi.org/10.3390/ani11010039

819 Turnbaugh, P. J., Ley, R. E., Mahowald, M. A., Magrini, V., Mardis, E. R., \& Gordon, J. I.

820 (2006). An obesity-associated gut microbiome with increased capacity for energy harvest. Nature, 444(7122), 1027-1131. https://doi.org/10.1038/nature05414

822 Vasey, N. (2005). Activity budgets and activity rhythms in red ruffed lemurs (Varecia rubra) on 823 the Masoala Peninsula, Madagascar: Seasonality and reproductive energetics. American

825 Villar, J., Cogswell, M., Kestler, E., Castillo, P., Menendez, R., \& Repke, J. T. (1992). Effect of fat and fat-free mass deposition during pregnancy on birth weight. American Journal of Obstetrics and Gynecology, 167(5), 1344-1352. https://doi.org/10.1016/S00029378(11)91714-1

829 Zhu, A., Sunagawa, S., Mende, D. R., \& Bork, P. (2015). Inter-individual differences in the gene $830 \quad$ content of human gut bacterial species. Genome Biology, 16(1), 82. 
Supplemental Table 1. Ethogram of behaviors for white-faced capuchin monkeys at Sector Santa Rosa, Costa Rica

\begin{tabular}{|c|c|c|c|}
\hline $\begin{array}{l}\text { Type of } \\
\text { Behavior }\end{array}$ & Specific Behavior & Code & Description \\
\hline \multirow{8}{*}{ Foraging } & $\begin{array}{l}\text { Forage: Insect } \\
\text { (Extractive) }\end{array}$ & EFI & Tearing branches, ripping bark \\
\hline & $\begin{array}{l}\text { Forage: Fruit } \\
\text { (Extractive) }\end{array}$ & $\mathrm{EFF}$ & Pounding, scrubbing, or breaking open fruits \\
\hline & Forage: Flower & FFL & Feeding on flowers \\
\hline & Forage: Fruit & FFR & Feeding on fruit \\
\hline & Forage: Insect & FIN & Feeding on insects \\
\hline & Forage: Other & FOT & Bromeliad leaves, pith, vertebrates \\
\hline & Forage: Visually & VFO & $\begin{array}{l}\text { Actively looking for food, including gleaning } \\
\text { insects while moving }\end{array}$ \\
\hline & Forage: Out of sight & FOS & $\begin{array}{l}\text { Monkey is foraging but mouth and/or forelimbs are } \\
\text { not visible }\end{array}$ \\
\hline \multirow{2}{*}{ Resting } & Rest (Solitary) & RES & Lying alone, not moving \\
\hline & Rest (Social) & SRE & Not moving, lying down \\
\hline Travel & Travel & TRA & $\begin{array}{l}\text { Travel; moving very rapidly, not pausing for } \\
\text { foraging or socializing }\end{array}$ \\
\hline $\begin{array}{c}\text { Social } \\
\text { Affiliation }\end{array}$ & Social (Active) & SAC & Monkeys are affiliative; allogrooming \\
\hline $\begin{array}{c}\text { Social } \\
\text { Aggression }\end{array}$ & Social (Aggressive) & SAG & Chasing, biting conspecifics \\
\hline \multirow{6}{*}{ Other } & Vigilant & VIG & Scanning intently at a long range (not for food) \\
\hline & Drink & DRI & Drink \\
\hline & Excretion & $\mathrm{EXC}$ & Excretion of feces, urine, or vomit \\
\hline & Self-Directed & SDI & Auto groom \\
\hline & Play & PLA & $\begin{array}{l}\text { Play: biting, chasing, hitting, bouncing, pushing, } \\
\text { pulling, etc. }\end{array}$ \\
\hline & Other & OTH & $\begin{array}{l}\text { Inter-group encounter, mobbing predator, sexual } \\
\text { behaviour }\end{array}$ \\
\hline
\end{tabular}


Supplemental Table 2. Generalized linear mixed models for resting and foraging behaviours. Model results and incidence rate ratios were computed for each prediction.

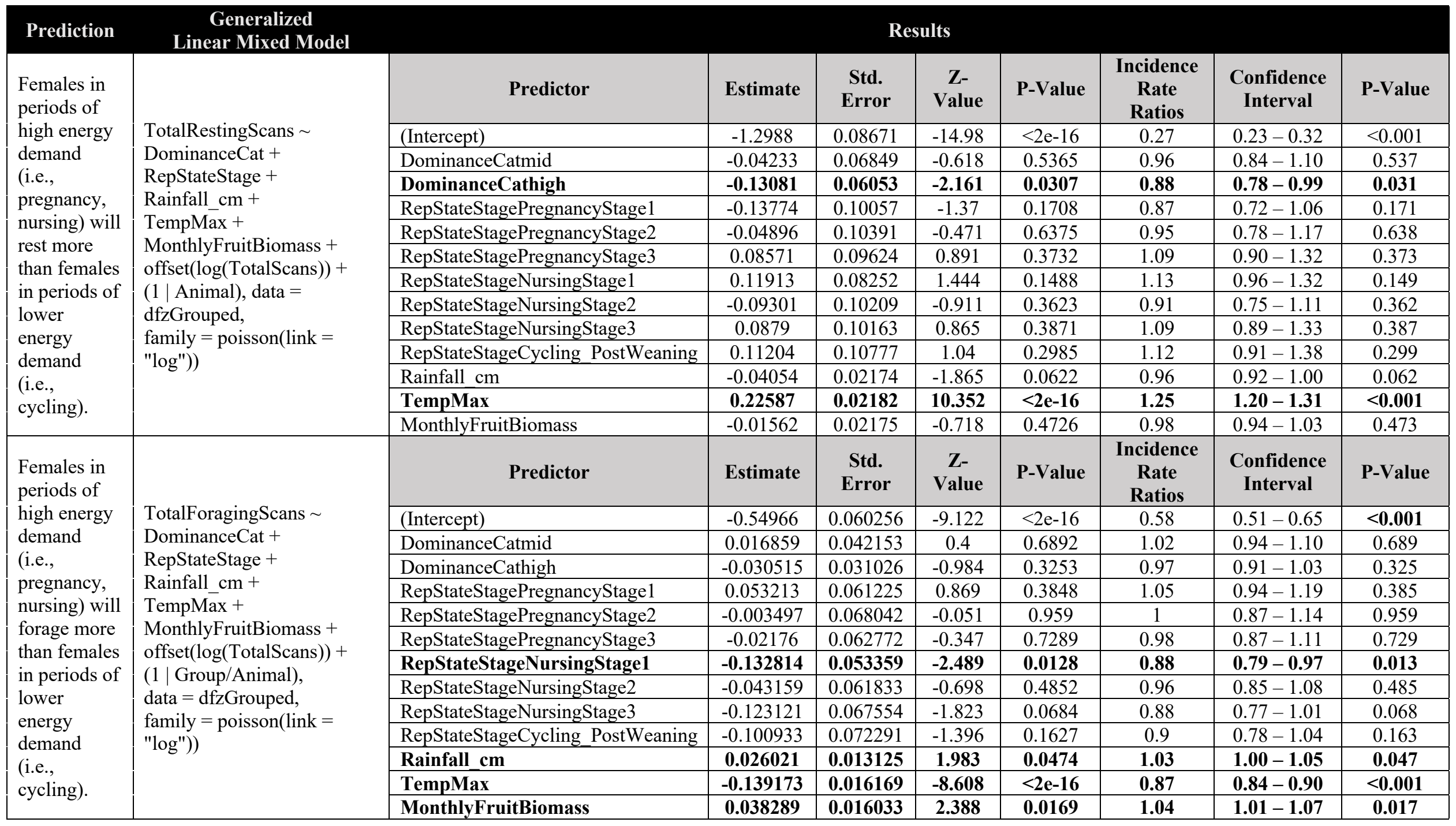


Supplemental Table 4. Linear mixed model outputs for richness and alpha diversity among fecal samples across reproductive states and PERMANOVA for Bray-Curtis dissimilarity among fecal samples.

\begin{tabular}{|c|c|c|c|c|c|c|c|c|c|c|}
\hline $\begin{array}{c}\text { Study } \\
\text { Component }\end{array}$ & $\begin{array}{c}\text { Model } \\
\text { Description }\end{array}$ & Model & & & & Results & & & & \\
\hline \multirow{6}{*}{\begin{tabular}{l|} 
Chao 1 \\
richness \\
among \\
reproductive \\
states
\end{tabular}} & \multirow{6}{*}{$\begin{array}{l}\text { Generalized } \\
\text { linear mixed } \\
\text { model with } \\
\text { negative } \\
\text { binomal } \\
\text { distribution }\end{array}$} & \multirow{6}{*}{$\begin{array}{l}\text { chao1 } \\
\text { ReproductiveStatus }+ \\
\text { scale(Rainfall })+ \\
\text { scale(TemperatureMax) }+ \\
(1 \mid \text { INDIVIDUAL), } \\
\text { data=metadataFilt) }\end{array}$} & Predictor & Estimate & $\begin{array}{l}\text { Std. } \\
\text { Error }\end{array}$ & $\begin{array}{c}\text { Z- } \\
\text { Value }\end{array}$ & $\begin{array}{c}\text { P- } \\
\text { Value }\end{array}$ & $\begin{array}{c}\text { Incidence } \\
\text { Rate } \\
\text { Ratios } \\
\end{array}$ & $\begin{array}{c}\text { Confidence } \\
\text { Interval }\end{array}$ & $\begin{array}{c}\text { P- } \\
\text { Value }\end{array}$ \\
\hline & & & (Intercept) & 4.76545 & 0.05274 & 90.356 & $<0.0001$ & 117.38 & $105.86-130.17$ & $<0.001$ \\
\hline & & & Nursing & -0.04053 & 0.09002 & -0.45 & 0.65256 & 0.96 & $0.80-1.15$ & 0.653 \\
\hline & & & Pregnant & -0.13895 & 0.09505 & -1.462 & 0.14377 & 0.87 & $0.72-1.05$ & 0.144 \\
\hline & & & scale(Rainfall) & -0.11816 & 0.03632 & -3.253 & 0.00114 & 0.89 & $0.83-0.95$ & 0.001 \\
\hline & & & scale(TemperatureMax) & 0.01115 & 0.03721 & 0.3 & 0.76439 & 1.01 & $0.94-1.09$ & 0.764 \\
\hline \multirow{6}{*}{$\begin{array}{l}\text { Shannon } \\
\text { alpha } \\
\text { diversity } \\
\text { among } \\
\text { reproductive } \\
\text { states }\end{array}$} & \multirow{6}{*}{$\begin{array}{l}\text { Linear mixed } \\
\text { model with } \\
\text { Gaussian } \\
\text { distribution }\end{array}$} & \multirow{6}{*}{$\begin{array}{l}\text { alphadiv } ~ \\
\text { ReproductiveStatus }+ \\
\text { scale(TemperatureMax })+ \\
\text { scale(Rainfall) }+ \\
(1 \mid \text { INDIVIDUAL), } \\
\text { data=metadataFilt) }\end{array}$} & Predictor & Estimate & $\begin{array}{c}\text { Std. } \\
\text { Error }\end{array}$ & $\begin{array}{c}\text { T- } \\
\text { Value }\end{array}$ & $\begin{array}{c}\text { P- } \\
\text { Value }\end{array}$ & $\begin{array}{c}\text { Incidence } \\
\text { Rate } \\
\text { Ratios } \\
\end{array}$ & $\begin{array}{l}\text { Confidence } \\
\text { Interval }\end{array}$ & $\begin{array}{c}\text { P- } \\
\text { Value }\end{array}$ \\
\hline & & & (Intercept) & 2.64774 & 0.0438 & 60.445 & -- & -- & $2.56-2.73$ & $<0.001$ \\
\hline & & & Nursing & 0.09473 & 0.07983 & 1.187 & -- & -- & $-0.06-0.25$ & 0.235 \\
\hline & & & Pregnant & 0.08834 & 0.08754 & 1.009 & -- & -- & $-0.08-0.26$ & 0.313 \\
\hline & & & scale(TemperatureMax) & 0.07061 & 0.03513 & 2.01 & -- & -- & $0.00-0.14$ & 0.044 \\
\hline & & & scale(Rainfall) & -0.05154 & 0.03443 & -1.497 & -- & -- & $-0.12-0.02$ & 0.134 \\
\hline \multirow{4}{*}{$\begin{array}{l}\text { Bray-Curtis } \\
\text { dissimilarity } \\
\text { among } \\
\text { reproductive } \\
\text { states } \\
\end{array}$} & \multirow{4}{*}{$\begin{array}{l}\text { PERMANOVA } \\
\text { using adonis } \\
\text { function } \mathrm{R} \\
\text { package vegan }\end{array}$} & \multirow{4}{*}{$\begin{array}{l}\text { distance(psState_filt, } \\
\text { method="bray") } \\
\text { ReproductiveStatus + } \\
\text { INDIVIDUAL + } \\
\text { scale(Rainfall) }\end{array}$} & Predictor & Df & $\begin{array}{l}\text { Sums of } \\
\text { Squares }\end{array}$ & $\begin{array}{c}\text { Mean } \\
\text { Squares }\end{array}$ & $\begin{array}{c}\text { F- } \\
\text { Value } \\
\end{array}$ & $\mathbf{R}^{2}$ & P-Value & -- \\
\hline & & & Reproductive Status & 2 & 0.614 & 0.30706 & 1.239 & 0.00789 & 0.186 & \\
\hline & & & Individual & 28 & 8.618 & 0.30779 & 1.242 & 0.11071 & 0.005 & -- \\
\hline & & & scale(Rainfall) & 1 & 0.711 & 0.71059 & 2.8674 & 0.00913 & 0.003 & -- \\
\hline
\end{tabular}


Supplemental Table 4. Generalized linear models to test variance inflation factor for ecological variables.

\begin{tabular}{|c|c|c|c|c|c|}
\hline \multirow{6}{*}{$\begin{array}{l}\text { Variance } \\
\text { inflation } \\
\text { factor test for } \\
\text { ecological } \\
\text { variables in } \\
\text { Resting } \\
\text { Model }\end{array}$} & \multicolumn{2}{|l|}{ Generalized Linear Model } & GVIF & \multirow{2}{*}{$\begin{array}{c}\mathrm{Df} \\
2\end{array}$} & \multirow{2}{*}{$\begin{array}{c}\mathrm{GVIF}^{\wedge}(1 /(2 * \mathrm{Df})) \\
1.019483\end{array}$} \\
\hline & glm(TotalRestingScans $\sim$ & DominanceCat & 1.080238 & & \\
\hline & $\begin{array}{l}\text { DominanceCat }+ \\
\text { RepStateStage }+\end{array}$ & RepStateStage & 1.41904 & 7 & 1.025314 \\
\hline & Rainfall_cm + & Rainfall_cm & 1.197425 & 1 & 1.094269 \\
\hline & MonthlyFruitBiomass + & TempMax & 1.280846 & 1 & 1.131745 \\
\hline & $\begin{array}{l}\text { offset }(\log (\text { TotalScans })) \\
\text { data }=\text { dfzGrouped, family = "poisson") }\end{array}$ & MonthlyFruitBiomass & 1.198814 & 1 & 1.094904 \\
\hline \multirow{6}{*}{$\begin{array}{l}\text { Variance } \\
\text { inflation } \\
\text { factor test for } \\
\text { ecological } \\
\text { variables in } \\
\text { Foraging } \\
\text { Model }\end{array}$} & \multicolumn{2}{|l|}{ Generalized Linear Model } & GVIF & Df & $\operatorname{GVIF}^{\wedge}(1 /(2 * D f))$ \\
\hline & \multirow{5}{*}{$\begin{array}{l}\text { glm(TotalForagingScans } \\
\text { DominanceCat }+ \\
\text { RepStateStage }+ \\
\text { Rainfall_cm }+ \\
\text { TempMax }+ \\
\text { MonthlyFruitBiomass }+ \\
\text { offset(log(TotalScans) }), \\
\text { data }=\text { dfzGrouped, family = "poisson") }\end{array}$} & DominanceCat & 1.080238 & 2 & 1.019483 \\
\hline & & RepStateStage & 1.41904 & 7 & 1.025314 \\
\hline & & Rainfall_cm & 1.197425 & 1 & 1.094269 \\
\hline & & TempMax & 1.280846 & 1 & 1.131745 \\
\hline & & MonthlyFruitBiomass & 1.198814 & 1 & 1.094904 \\
\hline
\end{tabular}

